\title{
LEITORES E LEITURAS EM AULAS DE HISTÓRIA: PROFESSORES, ALUNOS E A INVENTIVIDADE SOBRE O LIVRO DIDÁTICO
}

\author{
READERS AND READINGS IN HISTORY LESSONS: TEACHERS, STUDENTS \\ AND THE INVENTION OVER THE TEXTBOOK
}

Jeferson Rodrigo da Silva ${ }^{1}$

\begin{abstract}
RESUMO: Este texto é o resultado de uma pesquisa, iniciada em 2008, cujo objetivo era estudar as práticas de leitura do livro didático de História por professores e alunos. A partir do diálogo com autores relacionados à História da Leitura e com as ideias de Michel de Certeau, desenvolvidas, principalmente, na obra $A$ invenção do cotidiano, as práticas de leitura são apresentadas como práticas inventivas e criativas no cotidiano da sala de aula. Para o estudo da leitura, foi realizado um trabalho amplo, envolvendo a observação das aulas de História, a aplicação de questionários, entrevistas e a análise do livro didático utilizado. Para efeito comparativo, a pesquisa foi realizada com dois professores e duas turmas de $8^{a}$ série ( $9^{\circ}$ ano) do ensino fundamental de escolas diferentes e que utilizavam o mesmo livro didático. As conclusões permitiram constatar a existência de uma tensão entre o professor, o aluno e o livro didático em que a "credibilidade" atua como elemento fundamental das práticas de leitura do livro didático.
\end{abstract}

Palavras-chave: Livro didático. Práticas de leitura. História e ensino.

ABSTRACT: This text is the result of a research, begun in 2008, whose objective was to study the practice of reading of the History textbook by teachers and students. From the dialogue with authors related to the History of Reading and with the ideas of Michel de Certeau, developed mainly in the work The practice of everyday life, the reading practices are presented as inventive and creative in the everyday of the classroom. For the study of reading, an extensive work was undertaken, involving observation History classes, questionnaires, interviews and analysis of the textbook used. For comparison, the survey was conducted with two teachers and two classes of 8th grade (9th year) of different elementary schools which used the same textbook. The conclusions showed evidence that there is a tension between the teacher, the student and the textbook at which the "credibility" acts as a key element of the reading practices of the textbook.

Keywords: Textbook. Practices of reading. History and education;

1 Mestrando no Programa de Pós-graduação em História Social, linha História e Ensino, da Universidade Estadual de Londrina, bolsista CAPES e membro do GT "Ensino de História e educação - ANPUH/PR". 


\section{Apresentação}

No ano de 2008, realizamos um projeto de pesquisa vinculado ao curso de Especialização em História Social e Ensino de História na Universidade Estadual de Londrina, sob a orientação da professora Dra. Ana Heloisa Molina cujo objetivo era estudar as práticas de leitura que ocorriam na sala de aula de História. Este projeto objetivou, em um primeiro momento, as práticas dos alunos. "Como os alunos leem os livros didáticos?" foi a questão que nos motivou a pensar toda essa conjuntura, guiados, principalmente, pela ideia de que haveria, nas práticas dos alunos, algo que as caracterizasse como diferentes, individuais, particulares. Neste sentido, entendemos que o termo "Leituras inventivas" é o que permite melhor apresentar essa ideia.

Existe certo tom de obviedade quando dizemos que os alunos realizam leituras diferenciadas, pois há tempos discute-se que os conhecimentos históricos são apreendidos de forma ativa quando relacionados diretamente a certos elementos que passaram a ser discutidos em pesquisas e debates sobre o ensino de História: os conhecimentos prévios; os saberes tácitos; os conceitos substantivos e de segunda ordem; a cultura escolar; a aprendizagem significativa crítica; a cognição histórica e o desenvolvimento da competência narrativa são alguns dos elementos considerados pelos pesquisadores que discutem as práticas de ensino de História priorizando a produção de conhecimento histórico pelos alunos.

Desde os primeiros momentos da pesquisa, percebemos que este objetivo nos levava, inevitavelmente, à leitura do professor que, aos poucos, foi incluída na problemática inicial. A questão "Como os professores leem o livro didático?" agregou-se à questão anteriormente apresentada no sentido de visualizar essas leituras como práticas singulares. Da mesma forma, sabemos que os professores carregam consigo elementos que definem suas particularidades na prática educativa: saberes docentes; formação profissional; formação pessoal; transposição didática; a didática e a prática do ensino de História foram algumas das formas com que se discutiram e se discutem nos dias de hoje a constituição e a forma de 
aplicação, nas práticas em sala de aula, dos saberes do professor de História.

Fizemos essa apresentação com o intuito de trazer para o "palco", a dupla de leitores do livro didático que constituiu o objeto de análise de nossa pesquisa. Retomando a problemática inicial, mas agora com as diferenças que devem ser consideradas, podemos refazer a questão central da seguinte forma: "Como os professores e alunos leem os livros didáticos?". Não se trata apenas da soma de dois questionamentos distintos, pois a partir daqui, a dupla de leitores torna-se estrutural (MUNAKATA, 2002) e isso implica em considerarmos, a priori, a essencialidade dos dois no fenômeno "práticas de leitura em sala de aula".

Para finalizarmos, o estudo dessas práticas de leitura, levou-nos à necessidade de considerar um objeto a ser lido. Nesse sentido, o livro didático completa uma tríplice relação que constituiu o objeto de analise na pesquisa. Escolhemos este material porque o consideramos essencial nas práticas de ensino de História em sala de aula e, nesse sentido, abordar a materialidade do livro didático tornou-se pertinente pelo fato de permitir, ao leitor, compreender, além das próprias leituras de professores e alunos, o material que fora lido. Assim, analisar o texto, a impressão e a leitura (CHARTIER, 1990) permitiu com que vinculássemos este objeto cultural às práticas de leitura em sala de aula.

De modo pontual, o que será apresentado aqui é parte integrante daquele projeto de pesquisa. Nós abordaremos a opção teóricometodológica; o método de obtenção e análise de dados e; alguns elementos relacionados à conclusão do trabalho. Esta forma de apresentação tem duas justificativas: primeiramente, os limites deste artigo não são suficientes para uma análise pormenorizada e; segundo, este trabalho está diretamente ligado ao projeto que desenvolvemos no mestrado atualmente e todas as questões, considerações e conceituações estão sendo aprofundados para melhor articular toda a problemática dessa pesquisa. Em suma, este trabalho se insere em uma continuidade. 


\title{
Uma Trajetória, da História da Leitura das Práticas de Leitura Inventivas
}

A referência feita neste texto às práticas de leitura inventivas remete ao nosso esforço de compreensão das práticas de leitura de professores e alunos nas aulas de História. A constituição dessa problemática tem como ponto de partida as discussões de autores que se identificam com o campo historiográfico denominado História da Leitura e alguns dos diálogos possíveis entre eles e Michel de Certeau.

Sendo uma ramificação daquela que ficou conhecida pelos historiadores como a Nova História Cultural, a História da Leitura surgiu para dar conta de questionamentos envolvendo o interesse em entender como as pessoas liam e o que influenciava e determinava suas leituras. Muitos trabalhos nessa linha direcionaram-se para a produção e consumo de livros na Europa durante o século XVII e XVIII. Nesse mesmo fluxo de trabalhos, encontramos, em discussões realizadas por Roger Chartier, o problema central desse tipo de pesquisa:

\begin{abstract}
A questão é simples: como é que um texto que é o mesmo para todos aqueles que o lêem pode tornar-se um "instrumento de lid o contienda a sus lectores para ponerlos em diferencias, dando cada una sentencia sobre ella a sabore de su voluntad" [instrumento de discórdia e de brigas entre seus leitores, criando divergências entre eles e levando cada um, dependendo de seu gosto pessoal, a ter uma opinião diferente]? (CHARTIER, 1990, p. 122)
\end{abstract}

As palavras do autor levam a uma constatação bastante obvia: as leituras que ocorrem em relação ao livro são diferentes daquela leitura determinada pelo autor ou pelo editor do livro. Existe uma série de elementos que definem essas diferentes leituras como, por exemplo, o meio social e a bagagem de leituras anteriores (GOULEMOT, 1998).

Partindo dessa consideração, Chartier permite compreendermos as leituras como práticas inventivas e criativas quando afirma que:

Aparentemente passiva e submissa, a leitura é, em si, inventiva e criativa. Uma história abrangente da leitura e dos leitores deve, assim, considerar a variação, de acordo com o 
tempo e o local, das condições de possibilidade e das operações e feitos de tal invenção e criação. (CHARTIER, 2002, p. 31)

Para ampliar essa ideia de práticas de leitura entendidas como práticas inventivas e criativas, dialogamos com Michel de Certeau e suas ideias, relacionadas ao estudo do cotidiano, mas é importante lembrarmos que este pesquisador não se enquadra na História da Leitura e as referências ao livro e à leitura são aplicações metafóricas dos seus estudos sobre o cotidiano que, neste sentido, foram tomados de empréstimo para uma melhor visualização do tema:

\begin{abstract}
Se, portanto "o livro é um efeito (uma construção) do leitor", deve-se considerar a operação deste último como uma espécie de lectio, produção própria do "leitor". Esta não toma nem o lugar do autor nem um lugar de autor. Inventa nos textos outra coisa que não aquilo que era a "intenção" deles. Destaca-os de sua origem (perdida ou acessória). Combina os seus fragmentos e cria algo não-sabido no espaço organizado por sua capacidade de permitir uma pluralidade indefinida de significações. (CERTEAU, 2003, p. 264-265)
\end{abstract}

Sendo uma prática cotidiana, a leitura se apresenta como produção do leitor, portadora de um sentido diferente daquele pretendido pelo autor ou pelo editor. Neste sentido, abordamos as práticas de leitura em sala de aula pensando os leitores daquele ambiente, a saber: os professores e os alunos. Essa constatação permite supormos que eles praticam leituras diferentes do sentido pretendido pelo autor e/ou pelo editor do livro didático.

Considerando a leitura do livro didático por professores e alunos como prática inventiva, enfatizamos duas condições sine qua non: em primeiro lugar, essa prática de leitura é realizada pela dupla de leitores professor-aluno (MUNAKATA, 2002) sendo essa a relação que efetiva a prática; a segunda condição refere-se ao fato de que a prática de leitura é entendida como prática cotidiana, pois pensar dessa forma implica em analisarmos as práticas de leitura do livro didático em relação ao cotidiano da sala de aula. 
Conclusões precipitadas sobre as práticas de leitura como práticas inventivas podem dar a impressão de que o fato de serem entendidas como "inventivas" e "criativas" possibilita resultados infinitos. O conceito de invenção em uma análise desatenta pode se tornar desastroso quando partimos consideramos que, em um texto, qualquer leitura é permitida. Não há espaços para indeterminismos. Existe um conjunto de fatores que influenciam determinados tipos de leitura que, segundo Roger Chartier (1990), seriam a diversidade de suportes dos livros, o tipo de leitura, as interferências dos editores e as variações de tempo. Por esse motivo, não restringimos a pesquisa ao estudo das práticas de leitura do livro didático.

Para uma melhor definição das práticas de leitura como práticas inventivas e criativas, é necessário atentarmos aos limites que um livro impõe às leituras. Esses limites são definidos por Roger Chartier (1998) como protocolos de leitura. Toda vez que um livro é produzido, este carrega consigo regras, implícitas ou explicitas, que buscam guiar os olhos dos leitores, o que podemos chamar de uma leitura autorizada. É dentro desses limites que uma pessoa lê um livro seja ele qual for, incluindo-se também o livro didático.

Em Certeau, mesmo sendo entendidas como plurais, as práticas de leitura são delimitadas pelo que o autor define como um lugar:

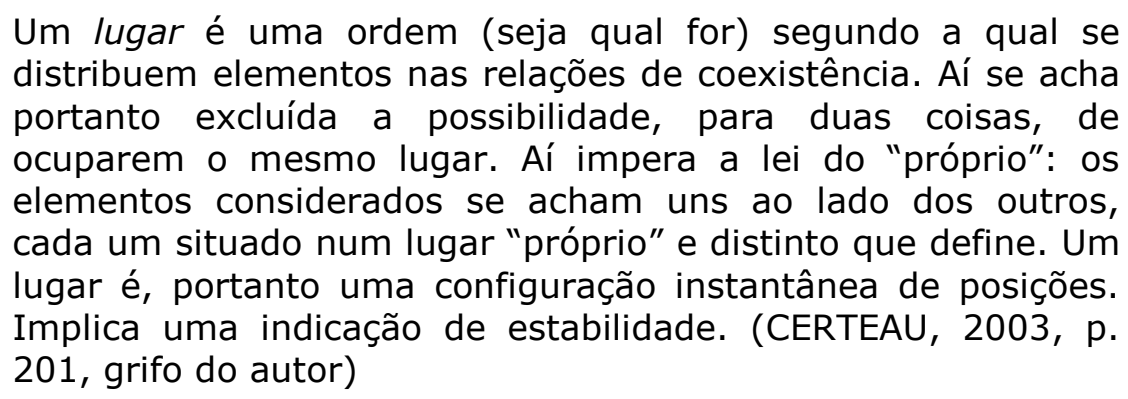

Na obra do mesmo autor, intitulada $A$ escrita da História, o lugar é definido como lugar social e pressupõe que o historiador, ao realizar sua pesquisa, condiciona-se à instituição a qual está vinculado porque esta delimita sua prática por meio de normas institucionais. "Toda pesquisa historiográfica se articula com um lugar de produção sócio-histórico, político e cultural." (CERTEAU, 2007, p. 66). 
Pensar as práticas de leituras como práticas inventivas, nesse sentido, implica em considerarmos esse lugar social. É possível entendermos o livro didático como um lugar social articulando este conceito com a ideia de protocolos de leitura de Chatier? Sim, mas vai além. A sala de aula também é um lugar a ser considerado no estudo dessas práticas. Qual dentre estes dois seria o lugar do leitor? Segundo Certeau:

[...] seu lugar [o do leitor] não é aqui ou lá, um ou outro, mas nem um nem outro, simultaneamente dentro e fora, perdendo tanto um como o outro misturando-os, associando textos adormecidos mas que ele desperta e habita, não sendo nunca o seu proprietário. Assim, escapa também à lei de cada texto em particular como à do meio social. (CERTEAU, 2003, p. 270, grifo do autor)

Com esta pequena abordagem da concepção teórica que integrou nossa pesquisa, é possível situarmos melhor a problemática trabalhada. Nesse momento, a questão que surge é aquela que não cessou de nos "incomodar" durante todo o trabalho realizado e, de certa forma, ainda habita nossas angústias juntamente com outros "fantasmas": como realizar isso na prática?

\section{Vendo as Coisas com s Próprios Olhos: um (In)Apreensível Objeto de Análise}

Tentando pensar o que seria necessário para estudarmos as práticas de leitura do livro didático, procuramos as formas de obtenção de dados mais produtivas neste sentido. O problema principal: como estudar uma prática que é efêmera, que se constitui como ação imediata e desaparece tão rápido quanto surge? Alguns pesquisadores que direcionaram seus esforços para o estudo das práticas de leitura no início do século $X X$, como Bittencourt $^{2}$ (2008) e DeNipoti (1998), recorreram a um dos únicos tipos de vestígios viáveis para isso: as anotações feitas à mão por professores e alunos nos manuais. Por que fizeram isso? Porque a prática de leitura já não

2 Esta obra corresponde à tese de doutorado da autora, intitulada livro didático e conhecimento histórico: uma historia do saber escolar, defendida no ano de 1993 na USP, sob a orientação da professora Dra. Raquel Gleser. 
mais existia, o que restava dela era sua economia (CERTEAU, 2003, 2007) materializada em letra morta.

Pensando nessa constatação e na possibilidade de tomarmos caminhos diferentes, recorremos aos estudos do tipo etnográfico (ANDRÉ, 2000; ANDRADE, 2006), pois entendíamos que ali haveria uma possibilidade de trabalhar com essa prática:

[...] ela recomenda o emprego de diferentes métodos de coleta de dados, obtidos por intermédio de uma variedade de informantes, em uma diversidade de situações e a subsequente triangulação das informações obtidas. Sugere também a focalização progressiva do estudo, isto é, de uma posição mais aberta no início da pesquisa, vão sendo definidos, ao longo do processo, aqueles aspectos específicos que serão aprofundados na coleta e na análise dos dados. (ANDRE, 2000, p. 57)

Assim, realizamos aplicação de questionários, observação de aulas, entrevistas com os professores das turmas e uma análise do livro didático utilizado.

A pesquisa se desenvolveu com duas turmas de $8^{a}$ serie ( $9^{\circ}$ ano) do ensino fundamental de escolas estaduais diferentes da cidade de Cambé-PR que utilizavam o mesmo livro didático: Projeto Araribá: História ${ }^{3}$. De forma conjunta com o pesquisador, cada professor definiu o conteúdo a ser trabalhado e utilizado na pesquisa. Em uma das turmas, observamos o trabalho com o tema "Guerra Fria" enquanto na outra, o tema "Os Efeitos da Globalização".

Para iniciar o trabalho com cada turma, preparamos um questionário objetivo com questões que pretendiam levantar o perfil sociocultural das turmas. Além disso, havia questões referentes ao relacionamento destes com seus respectivos professores e à impressão que eles tinham do livro didático de História. Por fim, adicionamos algumas questões gerais sobre cada conteúdo a ser trabalhado posteriormente. Sabemos que é improvável

3 O livro analisado pertence à coleção editada em 2006 pela editora Moderna. Projeto Araribá: História foi composto de quatro volumes que abordavam respectivamente: da evolução dos primeiros grupos humanos até a divisão do império romano no volume 1 (232 páginas); da formação da Europa feudal até a expansão colonial no volume 2 (248 páginas); do absolutismo inglês ao Segundo Reinado brasileiro no volume 3 (216 páginas); e da era do imperialismo até a nova ordem mundial no volume 4 (256 páginas). 
diagnosticar as práticas de leituras inventivas com questionários. Nosso objetivo era definir pontos iniciais que permitissem termos uma ideia do tipo de alunos envolvidos com a pesquisa.

Depois da aplicação do questionário, passamos para a etapa de observação das aulas. Durante todo o período em que foram trabalhados os conteúdos em sala, havia a presença do pesquisador nas aulas fazendo anotações de campo sobre as práticas observadas. As falas, as atitudes, os direcionamentos dos professores e as respostas dos alunos foram alguns dos elementos registrados durante o período. O que, ao final, resultou em um grande relatório. Neste processo de obtenção de dados, ressaltamos a importância do método da etnografia:

O pesquisador aproxima-se das pessoas, situações, locais, eventos, mantendo com eles um contato direto e prolongado. [...] não há pretensão de mudar o ambiente, introduzindo modificações que serão experimentalmente controladas como na pesquisa experimental. Os eventos, as pessoas, as situações são observadas em sua manifestação natural [...]. (ANDRÉ, 2000, p. 29)

Nesse sentido, tivemos a preocupação de observar as práticas em sala de aula sem atuar diretamente interferindo nelas ou criando situações idealizadas. Um dos grandes desafios para o trabalho, nesse sentido, foi a impossibilidade de conhecermos previamente os tipos de práticas que ocorreriam. Reafirmamos que este ainda é um risco necessário no trabalho que desenvolvemos no momento, pois a pesquisa das práticas de leitura, pensadas como práticas inventivas sob o referencial teórico-metodológico escolhido, faz dessa impossibilidade, uma característica inerente ao estudo.

Após termos realizado as observações, aplicamos um segundo questionário cujo objetivo era diagnosticar elementos de uma possível apreensão, por parte dos alunos, dos conteúdos trabalhados pelos professores. Diferentemente do primeiro questionário que priorizava as informações como elas eram definidas pelo livro didático, este segundo tomou por base aquilo que os professores pretendiam ao trabalhar 0 conteúdo. 
O último trabalho realizado diretamente nas escolas correspondeu às entrevistas com os professores das duas turmas. O objetivo dessas entrevistas era esclarecer determinados acontecimentos ocorridos na observação e levantar elementos que permitissem conhecer um pouco da formação dos professores, sua relação com o ensino de História e com as turmas participantes.

Todo o material obtido nesse processo de trabalho em campo foi analisado individualmente e depois articulado de forma cruzada em questões definidas no decorrer da pesquisa.

Até o momento, nenhuma das abordagens metodológicas apresentadas remete ao objeto cultural lido por essas turmas. Para essa tarefa, dedicamos uma atenção maior ao livro Projeto Araribá: História no sentido de analisá-lo pelos pressupostos da História da Leitura.

Indo na direção contrária às pesquisas que têm por foco a crítica ideológica de conteúdos, como aquelas realizadas na década de 80, nós realizamos uma análise do livro didático considerando este um objeto cultural complexo:

[...] é necessário enfatizar que o livro didático possui vários sujeitos em seu processo de elaboração e passa pela intervenção de professores e alunos que realizam práticas diferentes de leitura e de trabalho escolar. Os usos que professores e alunos fazem do livro didático são variados e podem transformar esse veiculo ideológico e fonte de lucro das editoras em instrumento de trabalho mais eficiente $e$ adequado às necessidades de um ensino autônomo. As práticas de leitura do livro didático não são idênticas e não obedecem necessariamente às regras impostas por autores ou editores ou por instituições governamentais. (BITTENCOURT, 1998, p. 73)

Dessa forma, podemos dizer que a pesquisa inseriu-se diretamente nas discussões relacionadas com a História Cultural. Para uma exemplificação do trabalho prático, apresentaremos alguns resultados da pesquisa. 


\section{Professores, Alunos e Livro Didático}

O processo de análise e apresentação dos resultados foi feito de forma comparativa entre as duas turmas que participaram da pesquisa. Apesar disso, mostraremos alguns resultados obtidos na turma denominada "turma A", cuja professora recebeu a denominação "Professora A". Como relatado anteriormente, o livro utilizado pela turma foi o Projeto Araribá: História.

Um dos aspectos que chamou nossa atenção foi o fato de termos percebido certa negação, por parte da professora, em assumir o livro como instrumento central. A utilização de outros materiais foi algo que ocorreu com frequência nas aulas observadas, mas apesar dessa constatação, não é possível afirmarmos que o livro didático fora negado. Ao invés disso, abordamos essa situação como uma tensão constitutiva da prática de leitura inventiva da "professora A". Em outras palavras, a prática de leitura da professora se caracterizava pelas constantes tentativas de fuga do que 0 livro propunha como conhecimento a ser ensinado.

Nesse sentido é pertinente observarmos o que disse a "professora A", na entrevista, quando perguntada sobre sua utilização do livro:

[...] ele não abrange tudo que precisa ser... que 0 planejamento do governo quer que você trabalhe.... Deu uma mudada muito grande e é linear, infelizmente. É o que o governo não quer que seja... mas ele apresenta [...] de forma linear, que não é o ideal, mas a gente não trabalha em linear. A gente acaba pegando o que tem ali... você vê que eu não uso muito o livro. Você deve ter percebido isso, né? Eu tenho o livro ali como um apoio só... eu mando eles lerem para eles tomarem conhecimento. (informação verbal) ${ }^{4}$

A professora defendeu a opinião de que o livro não dava conta do que deveria ser ensinado, embora fosse perceptível a interferência do lugar onde ela está, tentando definir sua prática, o livro foi utilizado como um roteiro para os conteúdos trabalhados dentro do tema "Guerra Fria". A constituição desse roteiro materializado em sequências de imagens

\footnotetext{
${ }^{4}$ Entrevista concedida no dia 12 de Novembro de 2008.
} 
apresentadas na TV Pendrive ${ }^{5}$ serviu de suporte para as práticas de leitura inventivas da professora.

Durante a observação das aulas, percebemos alguns momentos de tensão coletiva como, por exemplo, o que ocorreu durante as explicações a respeito da corrida espacial ${ }^{6}$ no momento em que eram apresentadas imagens da chegada do homem à Lua?.

Os alunos começaram a questionar a veracidade desses fatos ${ }^{8}$ e a professora prontamente mostrou alguns vídeos relacionados ao tema. A postura dela foi a de não assumir uma opinião clara, como ela mesma relatou na entrevista, permitindo aos alunos tirarem suas próprias conclusões: "Eu deixei no ar, você percebeu? Porque... é uma situação que eu mesma... às vezes eu me questiono. Ta?! Será que foi um golpe de marketing?? Será que não foi?? A.. a.. História diz que não! Né?[...]" (informação verbal) ${ }^{9}$.

Mas seria realmente possível a um indivíduo assumir posição de neutralidade frente a um determinado assunto? Um professor poderia fazer isso frente aos alunos? Em determinado momento dessa mesma aula, a "professora $A$ " acabou apoiando um aluno que dizia ser aquela uma jogada de marketing. Se observarmos essas práticas de leitura inventivas, podemos considerar a hipótese de que a professora A não acreditava na possibilidade de chegada do homem à Lua em 1969.

Concluímos que os conteúdos do livro didático e da própria sequência de imagens, caídos em descrença, possibilitaram a abertura para que os alunos questionassem e polemizassem a situação. Consideramos este o ápice das práticas inventivas da "professora $A$ " onde ela reduziu ao máximo seu papel de transmissor de conteúdos e realizou uma leitura inventiva

\footnotetext{
${ }^{5}$ No ano de 2008, as escolas estaduais do estado do Paraná receberam um televisor de 29 polegadas na cor laranja para cada sala de aula com compatibilidade para dispositivos USB e cartões de memória. É possível assistir a filmes, sequencias de imagens e ouvir arquivos de áudio através deste aparelho.

6 Aula observada no dia 20 de Outubro de 2008.

7 No livro didático dos alunos, o conteúdo era apresentado na página 163 de forma breve mencionando de forma cronológica alguns dos principais fatos relacionados ao avanço espacial dos Estados Unidos e União Soviética.

${ }^{8}$ A mídia tem explorado esse tema com a veiculação de documentários na TV, publicação de livros e divulgação de sites na internet, entre outros, que apresentam elementos justificando a chegada do homem à Lua em 1969 como sendo uma farsa.

${ }^{9}$ Entrevista concedida no dia 12 de Novembro de 2008.
} 
juntamente com os alunos na forma de explicação para aquilo que não era aceito.

Enfatizando a possibilidade de farsa, a professora abriu espaço para que eles pesquisassem fora da aula sobre o tema. Sobre a leitura da professora em relação a este fato, a aula do dia 21 de Outubro revela outros aspectos importantes. Nesta aula, determinados alunos trouxeram uma pesquisa sobre a veracidade da chegada do homem à Lua. Após uma pequena discussão sobre o assunto, a professora enfatizou que aquilo poderia ser uma jogada de marketing, e completou dizendo: "[...] que o homem pisou hoje todos concordam!?!" (informação verbal) ${ }^{10}$. A fala da professora contribui para a compreensão de sua postura e da leitura inventiva realizada na discussão do fato histórico.

No livro didático, a corrida espacial é o último item abordado da página 193. Apesar de extremamente resumido, a sequência das informações corresponde a sequência de imagens apresentadas na TV Pendrive.

Frisamos que a chegada do homem a Lua não foi problematizada nem pelo livro e nem pelas imagens exibidas. A constituição da ideia de chegada do homem à Lua pela professora foi uma construção baseada na negação do que fora apresentado.

Podemos dizer que, em partes, as práticas de leitura inventivas da professora tinham como objetivo a tentativa de evitar o conflito no momento em que ocorriam questionamentos por parte dos alunos, numa postura muito mais de apoio às contestações. É óbvio que, se o pensamento da professora a respeito do tema já estivesse constituído no momento da discussão, não haveria possibilidade de ocorrer o inverso.

Um ponto interessante aqui são os indícios de uma leitura inventiva que não acredita na chegada do homem à Lua em 1969, mas que a considera possível nos dias de hoje, embora não tenham ocorrido missões tripuladas, com objetivo de chegar à Lua, desde 1972.

Dentre as questões contidas nos questionários aplicados aos alunos, algumas evidenciaram a existência de credibilidade em relação às falas da

${ }^{10}$ Entrevista concedida no dia 12 de Novembro de 2008. 
professora. Aspectos da postura ativa da turma são revelados quando eles foram perguntados sobre a melhor forma de se aprender sobre o conteúdo "Guerra Fria": 64\% disseram ser melhor aprender através de debates entre professor e alunos. Para concluir a ideia que esses alunos têm em relação à professora, depois das aulas observadas, perguntamos o que eles acharam daquilo que foi aprendido: 93\% disseram que o conteúdo foi bom porque a professora soube explicar bem e $68 \%$ disseram que foi bom porque a professora conseguiu mostrar a importância do conteúdo. Mais uma vez destacamos que o aspecto "credibilidade" esteve presente em todas as aulas ministradas.

\begin{tabular}{|c|c|c|c|c|c|}
\hline $\begin{array}{l}\text { 23. Qual é a forma mais } \\
\text { interessante para } \\
\text { aprender sobre Guerra } \\
\text { Fria? }\end{array}$ & $\begin{array}{c}\text { Não } \\
\text { concordo de } \\
\text { forma } \\
\text { alguma } \\
\end{array}$ & $\begin{array}{c}\text { Não } \\
\text { concordo }\end{array}$ & $\begin{array}{l}\text { Mais ou } \\
\text { Menos }\end{array}$ & $\begin{array}{l}\text { Concor } \\
\text { do }\end{array}$ & $\begin{array}{c}\text { Concordo } \\
\text { Plenamen } \\
\text { te }\end{array}$ \\
\hline (a) Livros Didáticos & $4 \%$ & $18 \%$ & $46 \%$ & $29 \%$ & $4 \%$ \\
\hline $\begin{array}{l}\text { (b) Documentos e Fontes } \\
\text { Originais }\end{array}$ & $4 \%$ & $7 \%$ & $30 \%$ & $44 \%$ & $15 \%$ \\
\hline $\begin{array}{l}\text { (c) Aulas Expositivas do } \\
\text { professor }\end{array}$ & $4 \%$ & $4 \%$ & $32 \%$ & $46 \%$ & $14 \%$ \\
\hline $\begin{array}{l}\text { (d) Filmes e } \\
\text { documentários que falam } \\
\text { da Guerra Fria }\end{array}$ & $0 \%$ & $0 \%$ & $21 \%$ & $36 \%$ & $43 \%$ \\
\hline $\begin{array}{l}\text { (e) Debates entre } \\
\text { professor e alunos }\end{array}$ & $0 \%$ & $11 \%$ & $25 \%$ & $32 \%$ & $32 \%$ \\
\hline $\begin{array}{l}\text { (f) Apresentações de } \\
\text { trabalhos na sala de aula }\end{array}$ & $11 \%$ & $18 \%$ & $29 \%$ & $25 \%$ & $18 \%$ \\
\hline
\end{tabular}

Tabela 1 - Questão retirada do Questionário 1 aplicado à 29 alunos da "turma A" antes da observação das aulas sobre o tema "Guerra Fria" 


\begin{tabular}{|c|c|c|c|c|c|}
\hline $\begin{array}{l}\text { 05. O que você achou da } \\
\text { forma como aprendeu o } \\
\text { conteúdo Guerra Fria? }\end{array}$ & $\begin{array}{c}\text { Não } \\
\text { concordo } \\
\text { de forma } \\
\text { alguma }\end{array}$ & $\begin{array}{l}\text { Não } \\
\text { concor } \\
\text { do }\end{array}$ & $\begin{array}{l}\text { Mais } \\
\text { ou } \\
\text { Menos }\end{array}$ & $\begin{array}{c}\text { Concor } \\
\text { do }\end{array}$ & $\begin{array}{l}\text { Concor } \\
\text { do } \\
\text { Plena } \\
\text { mente }\end{array}$ \\
\hline $\begin{array}{l}\text { (a) Boa. Porque o professor } \\
\text { soube explicar muito bem o } \\
\text { assunto. }\end{array}$ & $0 \%$ & $0 \%$ & $7 \%$ & $39 \%$ & $54 \%$ \\
\hline $\begin{array}{l}\text { (b) Boa. Porque o professor me } \\
\text { fez perceber o quanto é } \\
\text { importante aprender este } \\
\text { conteúdo. }\end{array}$ & $0 \%$ & $4 \%$ & $29 \%$ & $54 \%$ & $14 \%$ \\
\hline $\begin{array}{l}\text { (c) Boa. Porque consegui } \\
\text { resolver os exercícios } \\
\text { facilmente. }\end{array}$ & $11 \%$ & $7 \%$ & $32 \%$ & $39 \%$ & $11 \%$ \\
\hline $\begin{array}{l}\text { (d) Não tão boa. Porque } \\
\text { poderíamos ter utilizado } \\
\text { mais o Livro Didático. }\end{array}$ & $32 \%$ & $54 \%$ & $14 \%$ & $0 \%$ & $0 \%$ \\
\hline $\begin{array}{l}\text { (e) Não tão boa. Porque } \\
\text { poderíamos ter utilizado } \\
\text { outros materiais na aula. }\end{array}$ & $29 \%$ & $43 \%$ & $21 \%$ & $7 \%$ & $0 \%$ \\
\hline
\end{tabular}

Tabela 2 - Questão retirada do Questionário 2 aplicado à 29 alunos da "turma A" após a observação das aulas sobre o tema "Guerra Fria"

Os resultados mostram que, mesmo em situações onde o professor apresentou desconhecimento de determinados pontos, o questionamento dos alunos não abalou a credibilidade que estes tinham pelos seus professores.

\section{Considerações Finais}

Dentro do que apresentamos neste texto, é possível constatarmos a existência de uma tensão entre o professor, o aluno e o livro didático, evidenciada nas práticas de leitura, que está intimamente relacionada com a credibilidade em relação aos três elementos que compõem a problemática central da pesquisa.

O trabalho desenvolvido permitiu conhecermos as reais possibilidades no estudo das práticas de leitura de professores e alunos em relação ao livro didático quando essas práticas são entendidas como práticas inventivas. 
Apesar do esforço, em diversos momentos foi possível compreendermos bem menos os detalhes e pormenores dessas práticas do que visualizar os seus indícios. O que, evidentemente, não minimizou a importância do processo, não apenas no sentido de "testar" a teoria de compreensão e o método de abordagem e análise dos dados, mas também no sentido de compreender até que ponto é possível desenvolvermos determinadas perspectivas nos debates sobre as práticas de ensino de História.

A forma como apresentamos este texto assemelha-se ao trabalho final e, como enfatizamos no início deste texto, esse esforço insere-se em uma continuidade, pois as considerações apresentadas não são definitivas, mas apenas uma parte do processo que, hoje, possibilita o desenvolvimento de nossa pesquisa de mestrado.

\section{Referências}

ANDRADE, Luísa T. Aula de história: cultura, discurso e conhecimento. 2006. 280 f. Dissertação (mestrado em Educação) - UFMG, Belo Horizonte, 2006.

ANDRÉ, M. E. D. A. de. Etnografia da prática escolar. 5 ed., São Paulo: Papirus, 2000.

BITTENCOURT, C. Livros didáticos entre textos e imagens. In. (Org.). O saber histórico na sala de aula. 2 ed. São Paulo: Contexto, 1998. p. 69-90.

Autêntica, 2008.

. Livro didático e saber escolar: 1810-1910. Belo Horizonte:

CERTEAU, M. de. A invenção do cotidiano: 1. artes de fazer. Petrópolis: Vozes, 2003.

2007.

A escrita da história. 2 ed., Rio de Janeiro: Forense Universitária,

CHARTIER, R. A história cultural: entre práticas e representações. Lisboa: Difel, 1990.

. Do livro à leitura. In: CHARTIER, R. (Org.). Práticas da Leitura. São

Paulo: Estação Liberdade, 1998. p. 77-106. 
As revoluções da leitura no ocidente. In ABREU, M. (Org.). Leitura, História e História da Leitura. Campinas: Mercado de Letras/ALB/FAPESP, 2002. p. 19-31.

DENIPOTI, C. A magna causa da educação. In XIV ENCONTRO REGIONAL DE HISTÓRIA - SUJEITO NA HISTÓRIA: PRÁTICAS E REPRESENTAÇÕES. V. 2., São Paulo: Editora da Universidade do Sagrado Coração, 1998. p. 85109.

GOULEMOT, J. M. Da leitura como produção de sentidos. In: CHARTIER, Roger (Org.). Práticas da Leitura. São Paulo: Estação Liberdade, 1998. p. 107-116.

MUNAKATA, K. Livro Didático: Produção e Leituras. In: ABREU, Márcia. (Org.). Leitura, História e História da Leitura. Campinas: Mercado de Letras/ALB/FAPESP, 2002. p. 577-594.

PROJETO ARARIBÁ: História. Moderna: São Paulo, 2006. 